\title{
Caracterización del material compuesto mármol-poliéster
}

\section{Characterization of material composite marble-polyester}

\author{
F. A. CORPAS IGLESIAS(*), F. J. IGLESIAS GODINO(*), S. CODINA SÁNCHEZ(*), J. M. RUIZ ROMÁN(*), \\ J. M. RUIZ PRIETO(*), C. ALONSO SANTOS ${ }^{(*)}$ \\ (*) E. U. P. de Linares, Universidad de Jaén \\ (•) E. T. S. I. de Minas. Univ. Complutense de Madrid
}

Fecha de recepción:: 25-II-02

Fecha de aceptación: 8-V-02

ESPAÑA

\section{RESUMEN}

En este trabajo, caracterizamos un nuevo material compuesto, formado con una mezcla de poliéster y de mármol blanco triturado. El propósito final es doble: por un lado obtener un material para aplicaciones lo suficientemente competítivas como para que se pueda iniciar un estudio económico de viabilidad, aumentando el rendimiento de la materia prima y mejorando las salidas laborales de las comarcas extractoras.

Para la caracterización del material se ha determinado el porcentaje adecuado de poliéster. Así como las propiedades mecánicas (flexión, compresión y dureza), quimicas, fatiga térmica y su influencia a la exposición solar.

De los resultados obtenidos, este material podría ser utilizado para ornamentación tanto de interior como de exterior.

PALABRAS CLAVE: mármol, materiales compuestos, poliéster, nuevos materiales de construcción, residuos

\section{INTRODUCCIÓN}

El mármol es un importante sector económico en la comarca de Macael, en el sur-oeste de España, que con una población próxima a los 50.000 habitantes, constituyen el $80 \%$ de la producción de mármol español, dando empleo directo este sector a 4.300 trabajadores, dedicándose el $33 \%$ de las empresas a la de extracción, el $46 \%$ a la transformación y el $21 \%$ restante como industrias artesanas (1)

A finales del siglo XX, se obtuvieron unas ventas estimadas de 44.000 millones de pesetas, extrayéndose 780.000 toneladas correspondientes a la variedad de «Blanco Macael», 200.000 toneladas de otras variedades de blan-

\section{SUMMARY}

In this work we characterize a new material composite, formed with a polyester and crushed white marble mixture. The final purpose is double: to obtain a material for applications sufficiently competitive after an economic viability study, increasing the yield of the main commodity, using waste marble and improving the jobs in the quarries area.

In order to characterized of material, we have determined the suitable porcentage of polyester. Also we have carried out a study of the mechanical (stretching, resistance to traction, hardeness and thermal fatigue) chemicals properties and solar radiation influence.

From the results obtained, we deduce then that this material could be used to inside and outside adorment.
KEYWORDS: marble, material composite, polyester, new consttruction material, residues

co y 400.000 toneladas de mármol de otros colores. Esto supone aproximadamente unas 420.000 toneladas de residuos que, en su gran mayoría, se vierten en escombreras ocasionando un grave impacto paisajístico y ambiental. Una utilización que se realiza de estos residuos es, después de un triturado inicial, como materia prima para la construcción, fabricación de pinturas y gomas, para plantas desulfuradoras así como para obtener carbonato cál$\operatorname{cico}(2)$

En este trabajo, aportamos una aplicación más a estos residuos, de forma que se reduzca el material vertido en las escombreras que genera la actividad extractora del mármol. Proponemos obtener un material compuesto utilizando poliéster como ligante y mármol como base de este material compuesto. 
Hemos escogido el poliéster por ser un polímero termoestable, muy conocido en la actualidad, con un coste razonablemente bajo (tiene un coste muy inferior a las resinas epoxídicas $(3,4)$ además de no necesitar utillajes complejos en su proceso de conformado, pues la etapa de curado se puede realizar a temperatura ambiente.

\section{PROCEDIMIENTO DE FABRICACIÓN}

El mármol utilizado ha sido proporcionado por la empresa "Triturados Blanco Macael" siendo su composición química prácticamente calcita en su totalidad $(98,55 \%$ CaC03). Triturados Blanco Macael Ofrece una amplia gama de triturados de mármol. En nuestro estudio, nos hemos centrado en los triturados de granulometría inferior; tipo polvo (Figura 1) en donde se muestra la distribución de las partículas que han pasado por el último ta$\mathrm{miz}(<0,9 \mathrm{~mm})$ y una microfotografía de una probeta realizada con esta granulometría ( $8 \%$ de poliéster), y tipo arenilla (Figura 2) en donde las partículas han pasado a través de un tamiz de 1,7 $\mathrm{mm}$ y no sobrepasan el último tamiz de 0,9 mm, aunque como se puede observar en la distribución granulométrica de la figura 2, hay presencia de partículas con granulometría inferior debido a que un mayor tiempo de permanencia entre los tamices eleva el coste. La microfotografía contigua muestra una probeta realizada con esta granulometría y un $8 \%$ de poliéster.

Para carecterizar este material compuesto hemos fabricado probetas de $15 \times 30 \times 60 \mathrm{~mm}$, para los ensayos a flexión, compresión y dureza superficial. También se han realizado ensayos de fatiga térmica, radiación solar, absorción de agua y de ataque químico. Este tamaño de próeta es muy adecuado para todos los ensayos anteriormente indicados.

\section{RESULTADOS EXPERIMENTALES}

\subsection{Determinación del porcentaje de poliéster}

En primer lugar hemos determinado el porcentaje adecuado entre el poliéster y el mármol, tanto para la granulometría polvo (Figuras 3 y 4) como para la granulometría arenilla (Figuras 5 y 6), fijando como parámetro de idoneidad sus resistencias mecánicas a la compresión, su módulo de flexión y a la dureza superficial (sólo para granulometría polvo).

Deestas gráficas podemos observar que para un porcentaje del $8 \%$ de poliester un incremento de éste no supone un incremento significativo de sus resistencias.

En cuanto a la dureza superficial (Figura 7) se han realizados ensayos de dureza Vickers sólo para la granulometría mármol polvo, por presentar con ésta un aspecto quizás más estético, además de presentar una mayor heterogeneidad que las muestras con granulometría arenilla.

Si observamos esta gráfica, para porcentajes inferiores al 7,5\% de poliéster se obtienen durezas superficiales inferiores a las de poliéster y del mármol puro. Este contrasenido aparente se puede explicar por la menor resistencia entre las partículas de mármol ante los esfuerzos de penetración, al presentar una débil cohesión entre las partículas de mármol por la poca cantidad de poliéster.

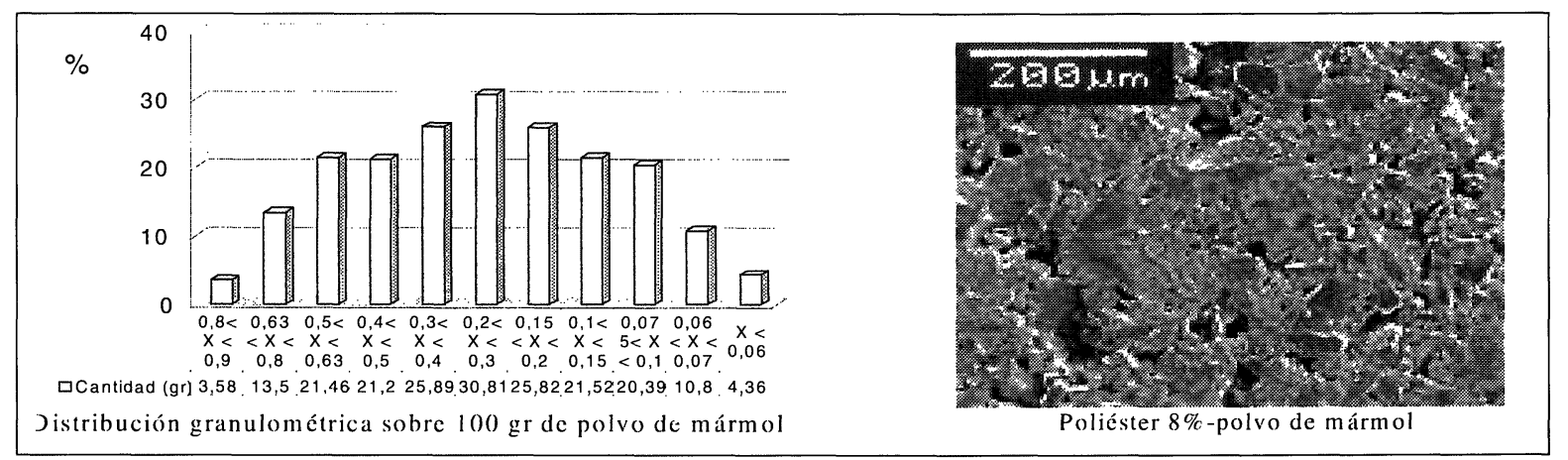

Figura 1.- Distribución granulométrica sobre $100 \mathrm{~g}$ de polvo de nármol. Poliéster con $8 \%$ de polvo de mármol.

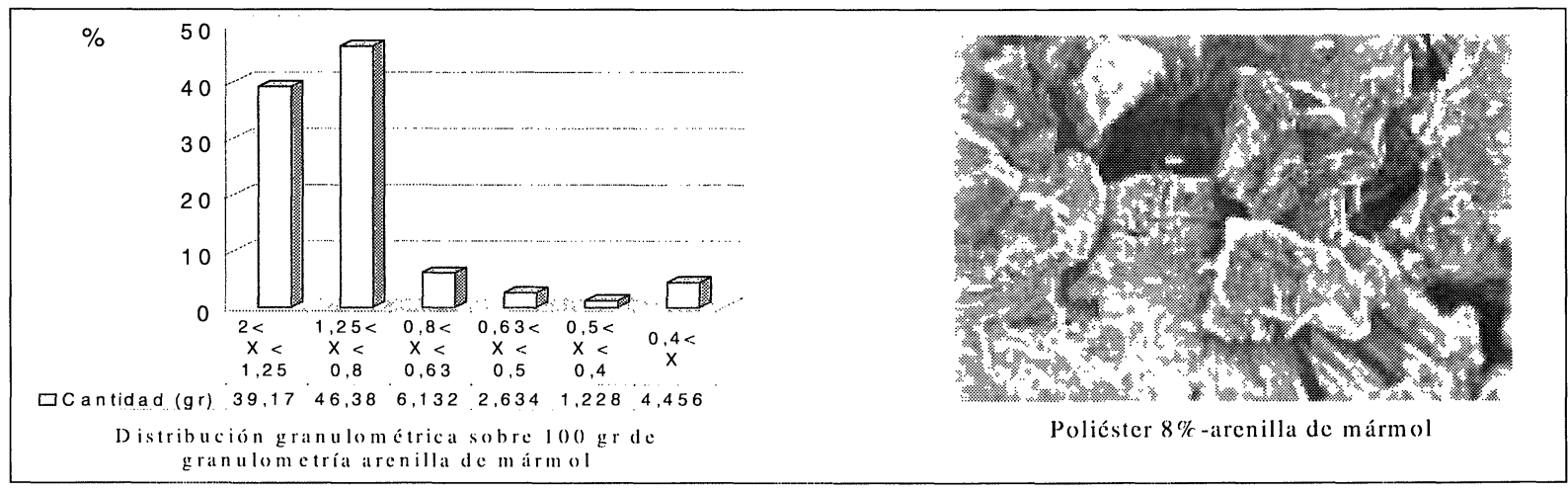

Figura 2.- Distribución granulométrica sobre $100 \mathrm{~g}$ de granulometría arenlla de mármol. Poliéster con $8 \%$ de arenilla de mármol. 


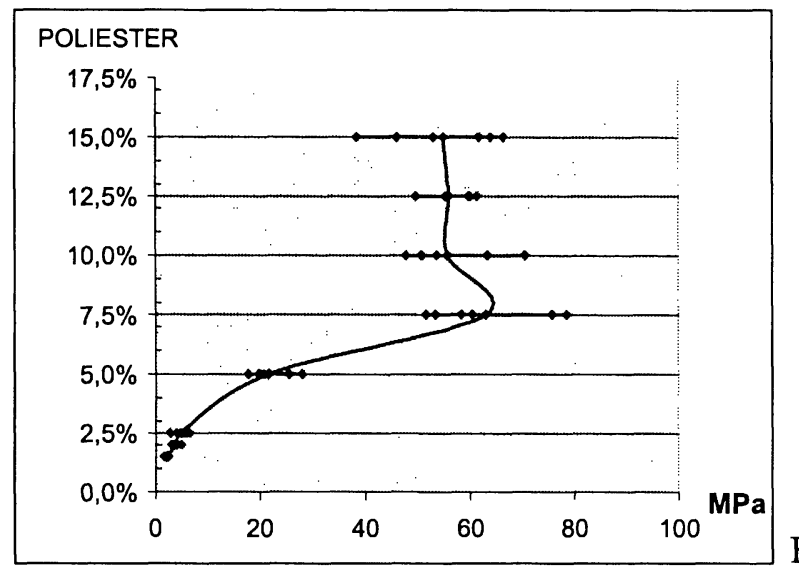

Figura 3.-Resistencia a compresión poliéster-polvo de mármol.

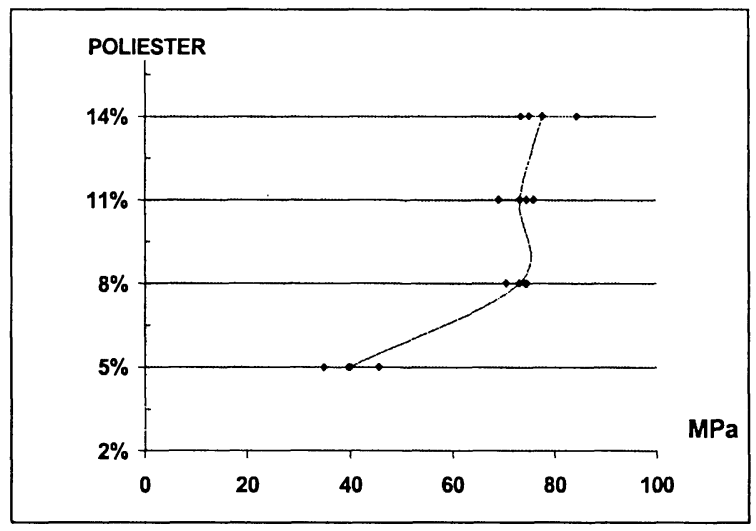

Figura 5.-Resistencia a compresión poliéster-arenilla de mármol.

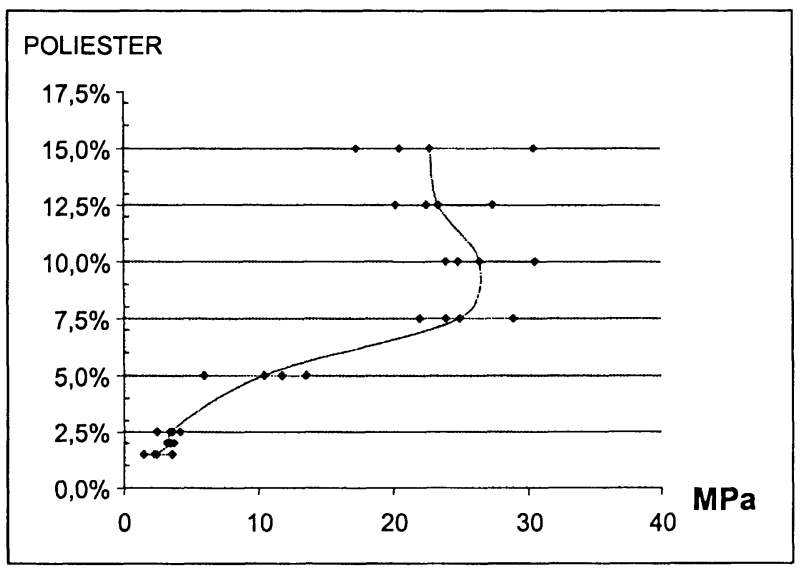

Figura 4.-Resistencia a flexión poliéster-polvo de mármol.

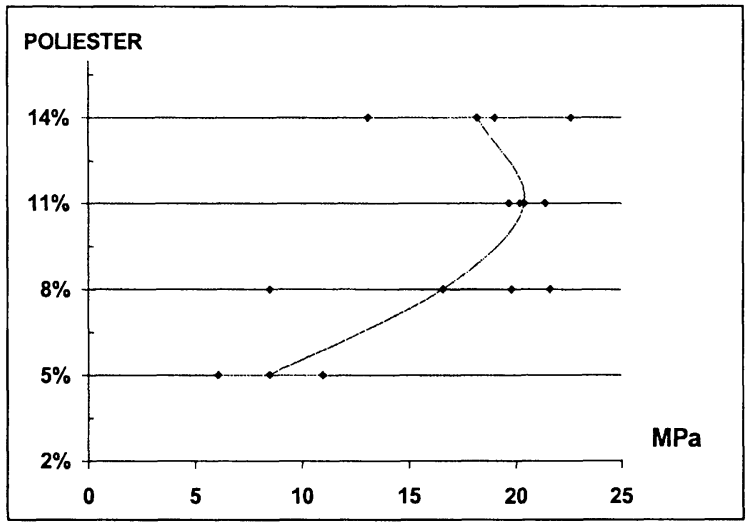

Figura 6.-Resistencia a flexión poliéster-arenilla de mármol.

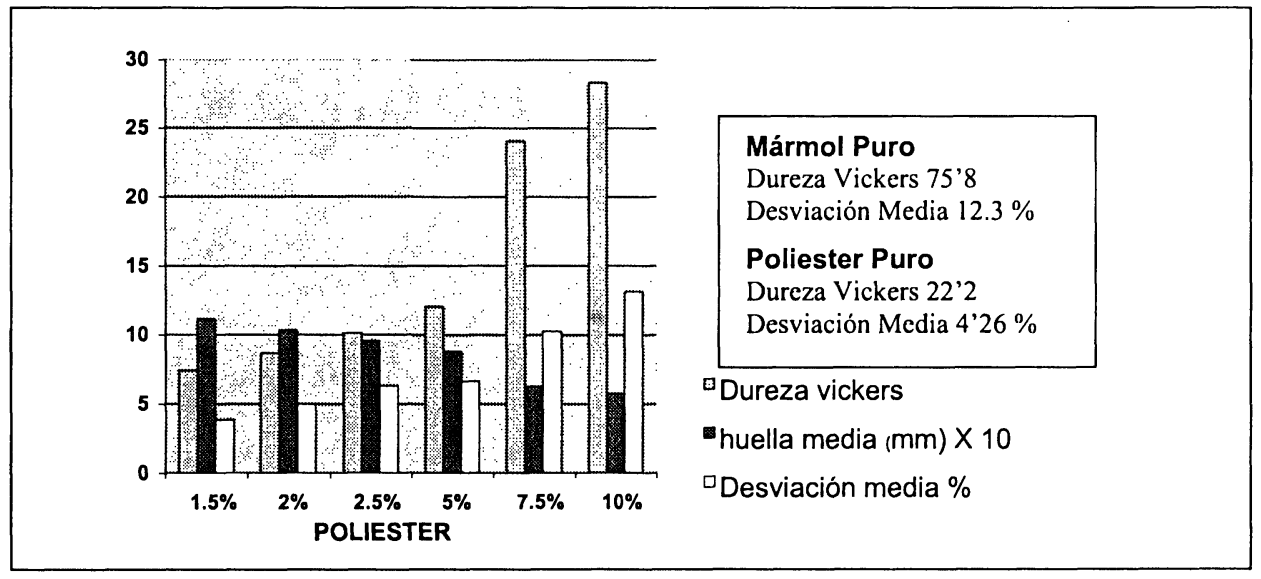

Figura 7.- Dureza Vickers poliéster-polvo de mármol.

\subsection{Influencia de la presión de compactación}

Con el porcentaje del $8 \%$ y para la granulometría polvo, una vez que los materiales se han mezclado e iniciado la polimerización, hemos estudiado el efecto de la compresión de compactación en el comportamiento mecánico de las probetas una vez que terminan de curar.
Como se puede observar en las Figuras 8 y 9, con una baja fuerza de compactación de $3.500 \mathrm{~kg}$ (presión efectiva de $19 \mathrm{MPa}$ ) se obtienen valores medios prácticamente constantes a los de ensayos con fuerzas de compactación superiores.

Sin embargo, observando el coeficiente de absorción (Figura 10) para la presión de compactación de $19 \mathrm{MPa}$ ob- 


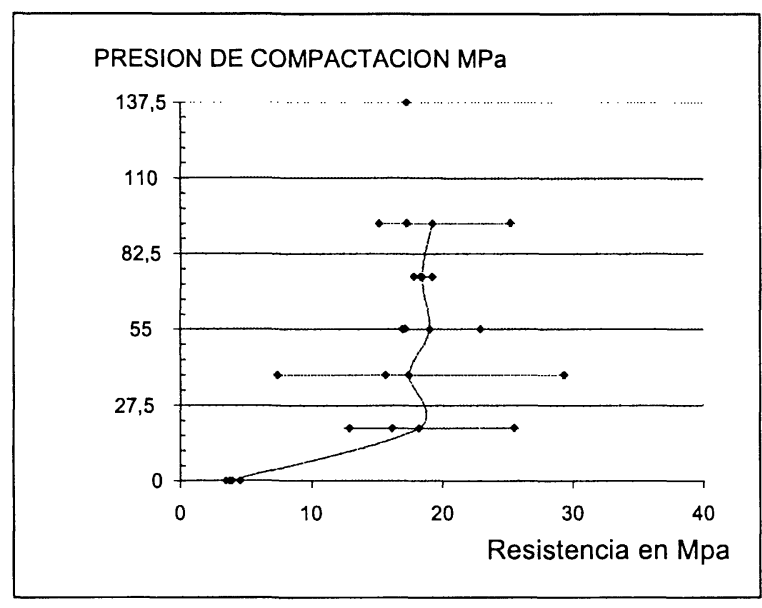

Figura 8.- Influencia de la presión de compactación sobre la resistencia a flexión $8 \%$ poliéster-polvo mármol

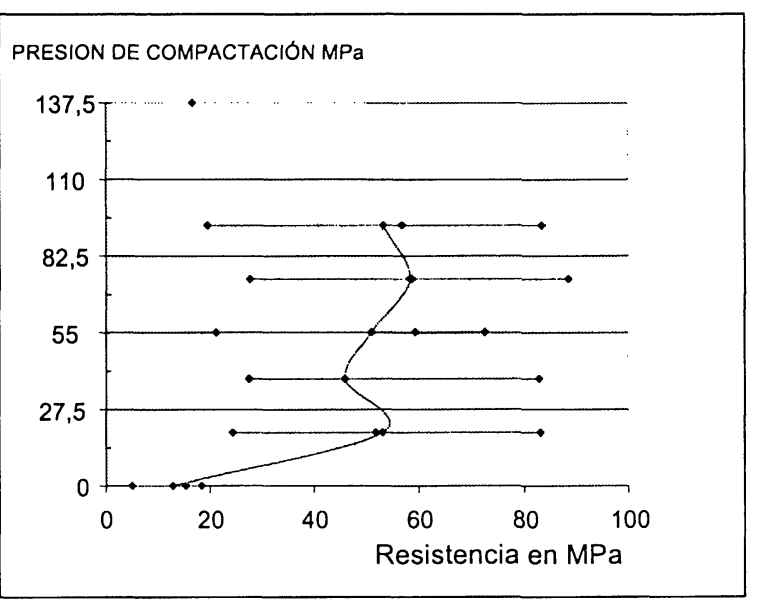

Figura 9.- Influencia de la presión de compactación sobre la resistencia a compresión $8 \%$ poliéster-polvo mármol

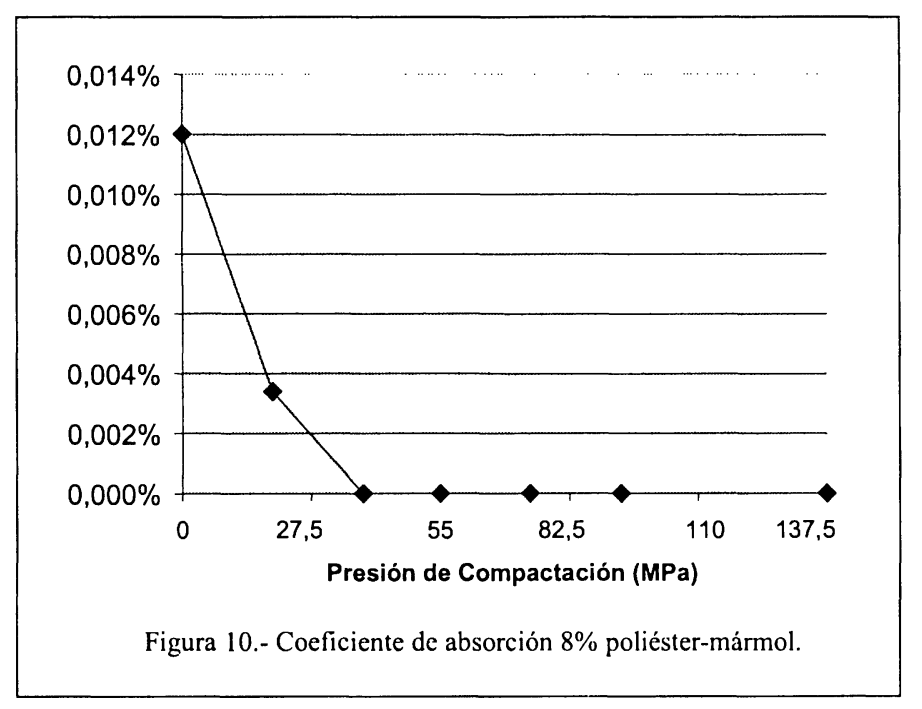

tenemos una ligera porosidad frente a la nula porosidad que se obtiene para mayores presiones (se eliminan totalmente los poros). Con lo que podemos concluir que la presión de compactación debe de tener un valor suficiente para eliminar los poros y que el poliéster "moje" a las partículas de mármol, no variando prácticamente su resistencia mecánica aunque presente cierta porosidad con presiones de compactación bajas.

\subsection{Fatiga térmica}

Se ha sometido a 5 probetas $8 \%$ poliéster - granulometría polvo a ciclos térmicos de 24 horas a $80^{\circ} \mathrm{C}$ seguidos de 24 horas a $-10^{\circ} \mathrm{C}$ (Figura 11) durante un tiempo de 20 días, al cabo de los cuales, se ha procedido a una inspección visual y microscópica, no obscrvándose cambios superficiales de aspecto ni fisuras. Posteriormente se han ensayado a compresión (75 MPa), flexión (26 MPa) y la dureza superficial (25,4 Vickers), sin producirse valores fuera de la dispersión obtenida en los ensayos sobre probetas sin tratar.

\subsection{Exposición solar}

Este ensayo (no normalizado, por lo que las conclusiones son a titulo indicativo) se ha realizado exponiendo 5 probetas $8 \%$ poliéster-granulometría polvo a la intemperie durante todo el mes de agosto de 2001 en la localidad de Linares (Jaén) sobre una superficie elevada y expuesta totalmente a la radiación solar.

Como se puede observar en la Figura 12, se aprecia una pérdida de coloración (blanqueado del poliéster) hecho que se ve reflejado en los histogramas de luminosidad 
de tres probetas (Figura 13), en donde en estos histogramas se representan la distribución de los píxeles de las imágenes escaneadas de las caras expuestas y no expuestas de cada probeta; en vertical la cantidad de píxeles sobre cada nivel de gris sobre el eje horizontal ( 0 negro y 256 blanco) apreciándose un desplazamiento hacia el blanco en la distribución de los píxeles que conforman la imagen de las caras escaneadas.

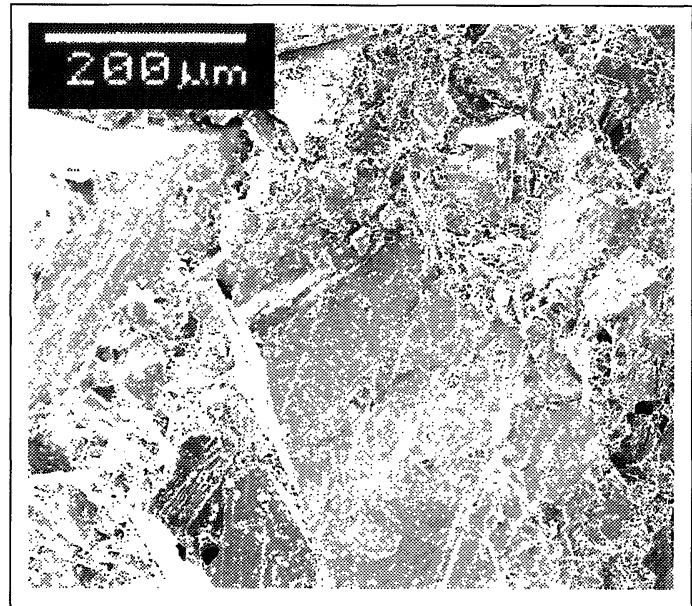

Figura 11.- Imagen en la que se puede observar que no se han producido deterioros en la interfase entre granos y el poliéster:
Observando su estructura microscópica (figura 14) no se aprecian cambios significativos entre la interfase entre el poliéster y las partículas de mármol.

Por lo que respecta a las características mecánicas, flexión 25,3 MPa y compresión $81 \mathrm{MPa}$, éstas están dentro de la desviación normal respecto de las probetas sin exponer a la radiación solar.

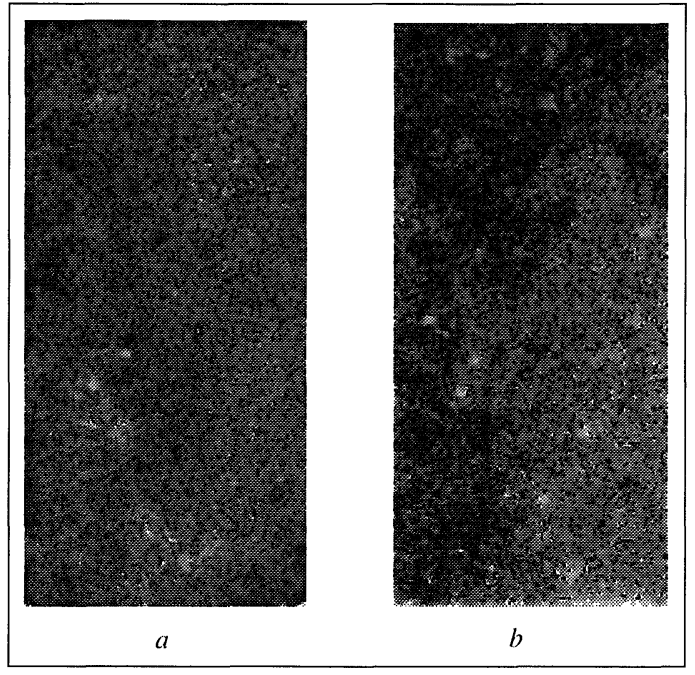

Figura 12.- a) cara expuesta; b) cara no expuesta.

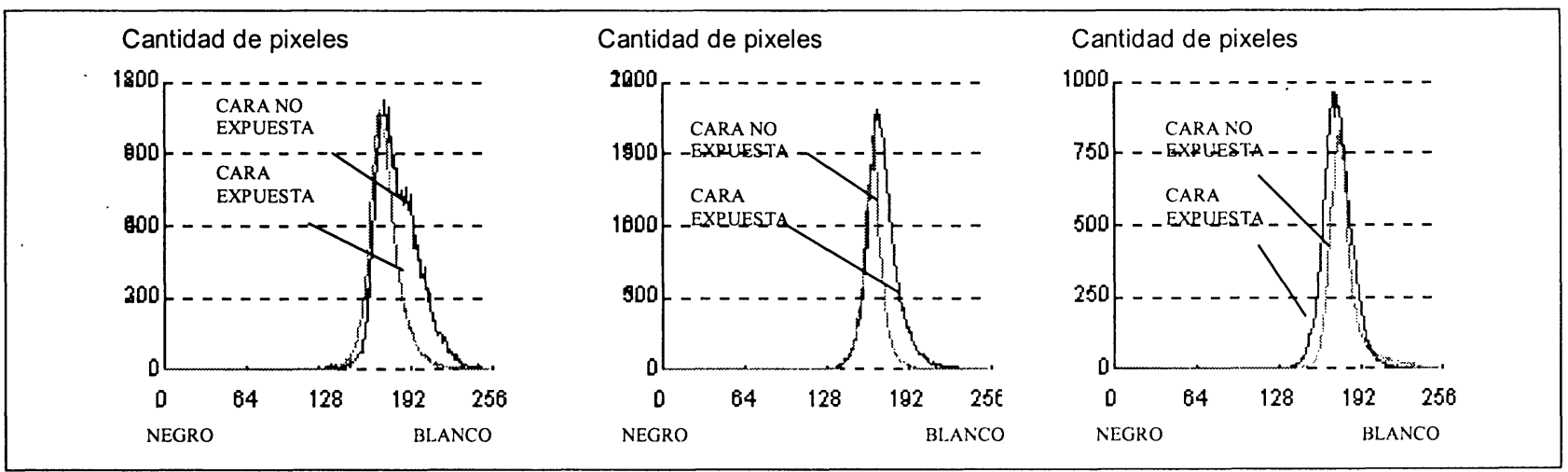

Figura 13.- Histograma de tres probetas $8 \%$ poliéster-polvo de mármol.

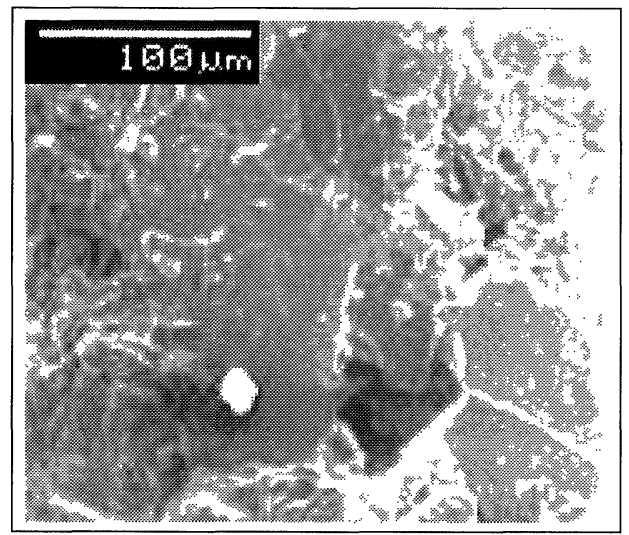

Figura 14.- Imagen en la que se puede observar; en su estructura microscópica, que no se han producido deterioros en la interfase entre granos y el poliéster. 


\subsection{Resistencia química}

Estos ensayos se han realizado basándonos en el método descrito en la norma ISO 10545-13 "Baldosas cerámicas. Determinación de la resistencia química”, consistente en la aplicación por inmersión en $200 \mathrm{cl}$ de los siguientes reactivos, valorándose a continuación sus propiedades mecánicas. Las muestras expuestas han sido $8 \%$ poliéstermármol.

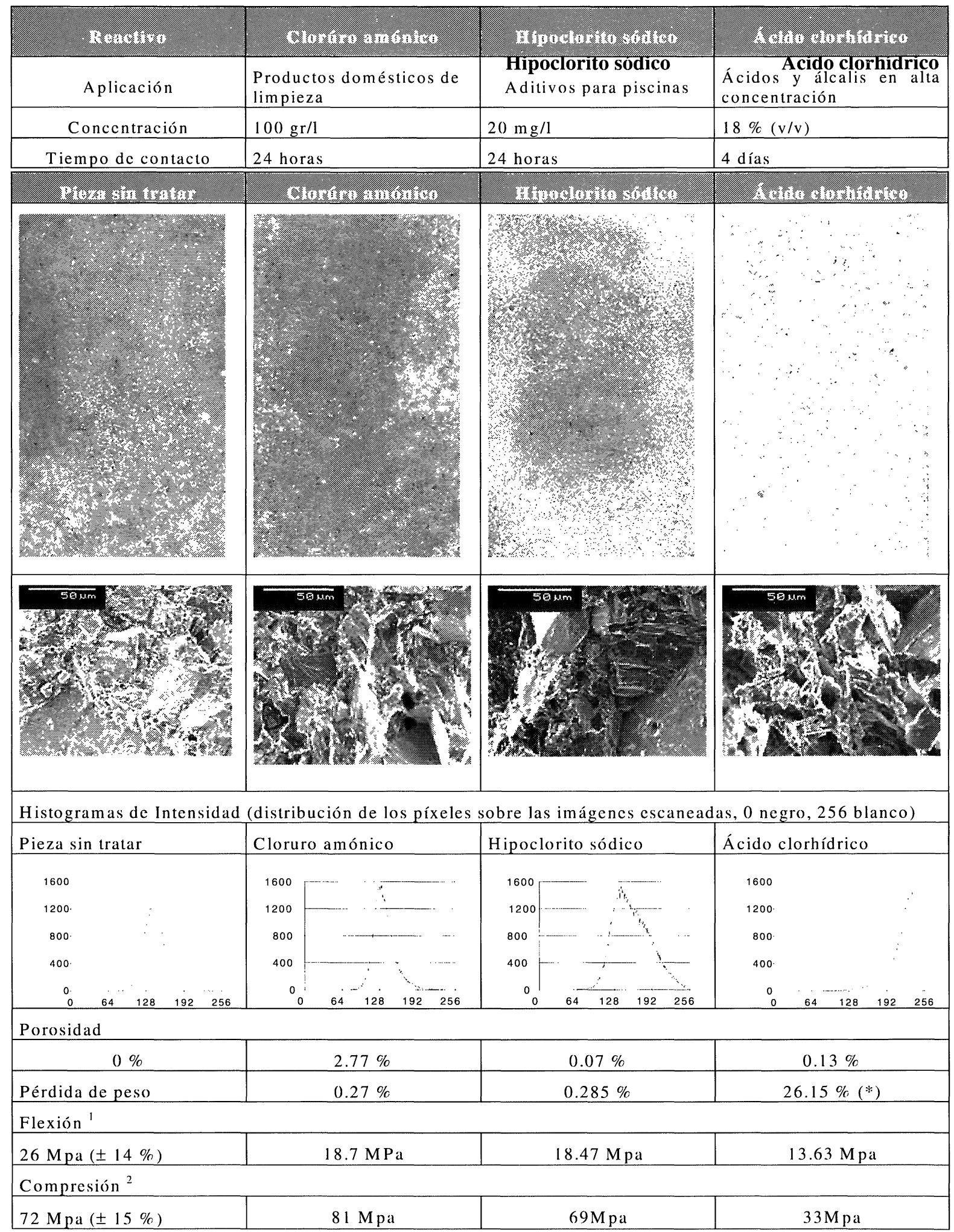

* La pérdida de material se produce superficialmente (en torno a 1,55 mm de profundidad) por lo que el núcleo no se ve afectado y, por lo tanto, sus propiedades mecánicas se reducen en proporción a esta pérdida de sección. 


\section{CONCLUSIONES}

El material compuesto formado por mármol blanco triturado, tanto de la granulometría polvo, como con la granulometría areniila, presentan unas propiedades aceptables, tanto mecánicas ante los esfuerzos de compresión, flexión y fatiga térmica, como a la exposición a los productos químicos y a la radiación solar. Por lo cual, este material sería idóneo para la fabricación de elementos ornamentales, tanto de interiores como de exteriores.

El coste de este material compuesto es de $0,13 € / \mathrm{kg}$ (mármol triturado con $8 \%$ poliéster), no obstante este valor es orientativo y tiene en cuenta solamente la materia prima sin tener en cuenta factores industriales ni otras consideraciones.

Queda por estudiar la aplicación combinada de estos materiales a través de materiales ligantes de construcción convencionales (morteros en base de cemento clásico o especiales) así como su comportamiento diferido con el tiempo, o bien a través de otros materiales ligantes no convencionales quizás a través de otros materiales poliméricos.

\section{BIBLIOGRAFÍA}

(1) Carretero Gómez, A. La comarca almeriense del mármol: una economía centrada en un único recurso. Revista de estudios regionales, $\mathrm{n}^{\circ} 48$ (1997) pp. 145-166.

(2) Benito Soria, (et al.). Manual de rocas ornamentales : prospección, explotación, elaboración y colocación. LOEMCO. Madrid. 1996.

(3) Corpas Iglesias, F. A; Codina Sánchez, Simón; Ruiz Roman, J.M; Ruiz Prieto, J.M.; García Cambronero, L. E; Alonso, Cristina. Exploitation of marble residues through material composite in a polymer matrix. Volume 6. Materials for Buildings and Structures. Wiley-VCH. 2000. ISBN: 3-527-30125-9.

(4) Corpas Iglesias, F. A; Codina Sánchez y otros. Using marble waste through composite materials made of polymeric matrix icce/8 tenerife 2001 . 